\title{
EDITORIAL
}

\section{Discourses at the Intersections of Disciplinary Knowledge, Pedagogy and Technology}

Teaching is about multiple discourses around disciplinary knowledge, the pedagogy and the medium of communication, and teachers are always trying to make sense of the intersections between and among these areas. These comprise intersections between knowledge about the subject matter, the pedagogy and the technology which is captured aptly by Koehler and Mishra, (2009), as Technological Pedagogical Content Knowledge (TPACK). This framework refers to the synergies among these bodies of knowledge and their interactions that influence and impact teaching and learning practices in any field and at any level. For effective, efficient and engaging teachers, in depth knowledge about all of these areas are crucial, making teaching a design science (Laurillard, 2012). Seeing teaching as a design science requires teachers to give careful thought to the design of the learning experience and its orchestration, and not simply imparting knowledge of the subject matter, or disciplinary knowledge (Naidu, 2016).

Articles in this first issue of Volume 12 of the OUSL Journal are examples of how university teachers from various disciplinary areas including education, language studies, social sciences, natural sciences and computer science, have brought discourses around content, pedagogy, and technology to bear upon their disciplinary practices.

Integration of Open Educational Resources (OER), a global trend gaining momentum in the Sri Lankan education system, is the focus of the first article by Kugamoorthy and Rajini. It explores the effect of an intervention programme on integrating OER in the teaching-learning process through the use of ICT, in supporting social change among school teachers in a postconflict social setting in Northern Sri Lanka. It reveals how this intervention has affected changing teachers' thinking patterns, social behaviours and social relationships in a positive manner. This case study is an illustration of a successful attempt to address complex interactions between pedagogy and technology in a specific context through the careful design of learning experiences, which has also supported social change. 
While effective interventions support changing thinking and practices of teachers, it is also important to investigate teachers' preparedness in applying those knowledge and skills developed. Teacher self-efficacy, which is teachers' beliefs in their own capabilities to organize and execute actions for effective teaching, is a key indicator of instructional preparedness of teachers. The study reported by Nawastheen, Wanasinghe and Senaviratne on self-efficacy beliefs of student-teachers of the Post Graduate Diploma in Education (PGDE) Programme of OUSL reveals that this professional development programme has contributed in developing teacher selfefficacy beliefs in terms of student engagement, instructional strategies, and classroom management, especially through its Educational Technology and Teaching Practice components. Their recommended strategies to foster teacher self-efficacy highlight the need to address the interplay of content, pedagogy and technology, through providing enabling conditions in teacher professional development.

Textbooks, a key instructional resource that teachers depend on during the teaching-learning process, and their role in influencing the thought patterns and beliefs of school children during their learning, is explored by Wijetunge, through a gender-analysis of the subject matter content of Government textbooks of English prescribed for senior secondary grades in Sri Lanka. Based on her findings which demonstrate demarcations of sexism in the content relegating females to a secondary supportive role and inadequate representation of female role models, the author argues that the textbooks, which is a key factor in exposing Sri Lankan learners to a new second language - English, need to be more gender-sensitive in their content, since the atmosphere created by a language determines the outlook of the learners towards the society. It implies the need of the appropriate selection of content and careful design of learning experiences for learners, according to the context.

Use of computer technology as an instructional strategy to support individuals with learning disabilities who may be facing challenges in processing information, interactions and communication, is a current positive trend. Punchimudiyanse and Meegama describe an innovative research where a computerized technique was designed to support word formation in Sinhala Sign Language (SSL) which is the preferred medium of communication amongst the aurally-handicapped Sinhala community in Sri Lanka. A database driven translator, which translates written Sinhala 
sentences into SSL sequences, is presented as a solution to certain deficiencies in the existing SSL techniques, which has been tested using a 3D avatar system. This provides a clear example of the affordance of technology linked with content and pedagogy, which has been creatively designed by these university teachers as a solution to support learners in a special context.

Despite the academic profession becoming increasingly demanding, engagement in volunteerism by university teachers beyond their academic obligations is an interesting phenomenon, as investigated by Adekalu, Krauss, Turiman, and Ismail. Their exploratory study, which attempted to understand the personal philosophies of volunteerism among professors at a Malaysian Research University revealed that three key factors - individual orientation and exposure; religious beliefs; and work related identities, contributed to this. Engagement in volunteering activities was also found to foster recognition for academics in their fields of expertise. This case study provides some useful insights into the effect of volunteerism on enhanced performance in scholarly and research activities of university teachers.

The remaining two papers in this issue exemplify instances of application of disciplinary knowledge by scholars to design solutions through research to address real life situations. The study by Gnanapragasam uses mathematical modelling and time series analysis to forecast a health issue - Leptospirosis, a zoonotic infectious disease, generally known as rat fever, which is becoming a major health threat in Sri Lanka. Human Leptospirosis cases in the Western province of Sri Lanka are modelled using Seasonal Autoregressive Integrated Moving Average (SARIMA) and the fitted model is used to forecast leptospirosis cases in the Western province that would be useful in planning for future control programmes of the disease.

Similarly, the final paper in this issue deals with an experiment related to disciplinary knowledge in food science. Research has proven that addition of probiotics - live microbial that beneficially affects the hosts by improving its intestinal microbial balance when administrated in adequate amounts to foods, results in certain health benefits. This has resulted in a growing interest in probiotic food products. Fasreen, Perera and Weerahewa report their study aimed at determining the survivability of probiotic bacteria Lactobacillus casei431 in finger millet based beverage throughout refrigerated storage. It is revealed that sensory acceptable finger millet 
based fermented probiotic beverage can be developed using L.casei431 ${ }^{\circ}$ that could serve as a ready to drink functional beverage under refrigerated storage.

Despite the diversity of articles in this issue, it is clearly visible that in essence, all research studies have dealt with the synergies between two or more constructs of different forms of knowledge in relation to content, pedagogy and technology. We hope that collectively, these articles offer you an opportunity to engage in a critical conversation about the affordances of each of these attributes discussed in the articles. They also highlight the significance of promoting scholarship and research in multiple disciplines along with Open and Distance Learning (ODL), to enhance collaborative thinking and practices among practitioners in higher education, which is the aim of OUSL Journal.

We appreciate the valuable contributions of all authors and reviewers of this issue, and hope that engaging in this multidisciplinary discourse would stimulate thinking and further dialogue among our readers about synergizing disciplinary knowledge, pedagogy and technology. We always welcome your feedback and suggestions for further improvement of the journal. Enjoy!

Shironica P. Karunanayaka

Editor-in-Chief, OUSL Journal

email: spkar@ou.ac.lk

http://orcid.org/0000-0003-1995-8828

\section{References}

Koehler, M. J., \& Mishra, P. (2009). What is technological pedagogical content knowledge? Contemporary Issues in Technology and Teacher Education, 9(1), 60-70.

Laurillard, D. (2012). Teaching as a design science: Building pedagogical patterns for learning and technology. New York: Routledge

Naidu, S. (2016). Technology, education and design: The sciences of the artificial. In ICT integrated teacher education. M.N. Panigrahi (Ed.). pp. 20-30. New Delhi: CEMCA. 